\title{
A unidade lexical funda: dados geolinguísticos evidenciando marcas históricas no interior do Mato Grosso do Sul
}

\author{
Beatriz Aparecida Alencar \\ Instituto Federal de Mato Grosso do Sul (IFMS), Campo Grande, Mato Grosso do Sul, Brasil ${ }^{1}$ \\ bia83_12@hotmail.com
}

DOI: http://dx.doi.org/10.21165/el.v46i1.1703

\begin{abstract}
Resumo
Corumbá e Ladário são cidades antigas em Mato Grosso do Sul. Em decorrência de características históricas, a língua portuguesa falada nessas localidades apresenta marcas distintas em relação ao restante do estado. Neste estudo, discutimos o comportamento do item lexical funda como denominação do "brinquedo feito de uma forquilha e duas tiras de borracha que os meninos usam para matar passarinhos", com base em dados geolinguísticos de dois atlas, o Atlas Linguístico de Mato Grosso do Sul (OLIVEIRA, 2007) e o Atlas Linguístico de Corumbá e Ladário (ALENCAR, 2013). O estudo discute fatores que possam justificar a permanência da variante lexical funda no falar dos sul-mato-grossenses, considerando, para tanto, aspectos da relação entre história, ambiente e norma lexical regional.
\end{abstract}

Palavras-chave: léxico; funda; atlas linguístico; Mato Grosso do Sul.

La unidad léxica honda: datos geolingüísticos evidenciando marcas históricas en el interior de Mato Grosso do Sul

\section{Resumen}

Corumbá y Ladário son ciudades antigüas ubicadas en Mato Grosso do Sul. Debido a las características históricas, la lengua portuguesa hablada en estos lugares presenta algunas diferencias notables en comparación al estado. En este estudio, discutimos el comportamiento del ítem léxico funda, para nombrar el "brinquedo feito de uma forquilha e duas tiras de borracha que os meninos usam para matar passarinhos". Para esto, utilizamos los datos geolingüísticos de dos atlas, Atlas Lingüístico de Mato Grosso do Sul (OLIVEIRA, 2007) y el Atlas Lingüístico de Corumbá y Ladário (ALENCAR, 2013). El estudio discute factores que puedan justificar la permanencia de la variante léxica funda en el habla de los habitantes de Mato Grosso do Sul, considerando, los aspectos de la relación entre historia, ambiente y norma léxica regional.

Palabras-clave: léxico; honda; atlas lingüístico; Mato Grosso do Sul.

\section{Caminhos da cultura e da linguagem}

As demarcações geográficas nem sempre envolvem mudanças nos hábitos e nos costumes da população, fenômeno que pode ser observado em especial em áreas de fronteira que, apesar de delimitarem nacionalidades diversas, em alguns casos, não evidenciam grandes contrastes entre a população e os seus respectivos moradores. Essa realidade acontece no estado de Mato Grosso do Sul, que recebe forte influência, por exemplo, da culinária do Paraguai, representada pela chipa, pela sopa paraguaia e,

\footnotetext{
${ }^{1}$ Docente do Instituto Federal de Mato Grosso do Sul e Doutoranda do Programa de Pós-Graduação em Letras da Universidade Federal de Mato Grosso do Sul (UFMS - Três Lagoas).
} 
sobretudo, pela preferência dos sul-mato-grossenses pelo mate gelado, denominado tereré.

Além dos hábitos de um grupo social, são ainda mais difíceis de serem delimitadas em uma cultura questões inerentes ao léxico. Acredita-se que algumas marcas acabam por se perpetuar no vocabulário dos habitantes de determinadas localidades em decorrência da própria história social e, consequentemente, apontarem para a indissociável relação entre língua e história. Para demonstrar isso, discutimos, neste trabalho, a questão das ocorrências da unidade lexical funda na língua falada pelos sulmato-grossenses com base em trabalhos dialetológicos realizados, particularmente, nos municípios de Corumbá e Ladário que atestam o uso da unidade lexical funda na fala da população desse rincão do Brasil.

Buscam-se, ainda, dados que visem a contribuir para: i) elencar fatores que possam justificar a permanência do item lexical funda (com datação a partir do século XIV) no falar dos habitantes de Corumbá e Ladário - Mato Grosso do Sul e ii) analisar o item lexical assinalado com ênfase na relação entre o seu uso regional e a história social das localidades. Para auxiliar a análise, serão consultados dicionários (gerais, etimológicos, regionais) de Língua Portuguesa produzidos em diferentes momentos da história da língua.

\section{Mato Grosso do Sul: o histórico do território}

O Estado de Mato Grosso do Sul é constituído por cidades bastante 'jovens' e cidades bem 'antigas', originadas antes da divisão do estado de Mato Grosso e consequente criação da nova unidade federativa, no ano de 1977.

Apesar de uma existência bastante curta enquanto estado, a parte do território que se tornaria o Mato Grosso do Sul, durante vários anos, foi alternando seus contatos com o colonizador europeu, ora sendo conhecido pelos exploradores, ora esquecido quando da unificação das coroas de Portugal e Espanha e de diferentes momentos da história da região. Desde remotas épocas, essa faixa de território foi caminho de acesso a diferentes regiões da América, como atesta a assertiva a seguir.

O fato é que por Mato Grosso do Sul passaram numerosas bandeiras, em direção ao norte, ao Paraguai e ao Peru; na segunda metade do século 17, as regiões do Iguatemi, do Ivinhema, a serra de Maracaju e a Vacaria eram bem conhecidas dos bandeirantes, principalmente nas suas rotas fluviais (CAMPESTRINI; GUIMARÃES, 1991, p. 15).

As preocupações referentes à ocupação da área só começaram a ocorrer com o avanço da defesa do território pertencente à coroa espanhola nas áreas limítrofes. Entre essas localidades que demarcaram a divisão territorial no Centro-Oeste do Brasil, destacase a cidade de Corumbá, que é considerada, do ponto de vista geográfico, "a presença portuguesa, nas vizinhas espanholas no Cone Sul" (ITO, 2000, p. 66).

A cidade de Corumbá localiza-se no extremo oeste de Mato Grosso do Sul, tendo como limites territoriais dois países sul-americanos: Bolívia e Paraguai. Em virtude da sua localização geográfica fronteiriça, a região acabou tendo, no decorrer da sua existência, muito contato com os países vizinhos e pouca ligação com o interior do Brasil, em decorrência do difícil acesso à região e por estar circunscrita ao bioma Pantanal, consequentemente, acabou por ficar, de certa forma, protegido de migrantes brasileiros 
até meados do século XX, quando da chegada dos meios de transporte terrestres. A seguir, recuperamos de forma pontual alguns dados sobre a colonização do Oeste de Mato Grosso do Sul.

\subsection{Corumbá: a gênese da localidade}

A atitude do então governador da Capitania do Mato Grosso, o general Luis de Albuquerque de Melo Pereira e Cáceres (1772), ao mandar construir uma fortaleza para proteção do território, conhecido hoje como o Forte Coimbra, foi fundamental para a manutenção da fronteira e para o surgimento de Corumbá, uma das mais antigas cidades do Estado ${ }^{2}$.

O importante é que se passava a ocupar a margem direita do Paraguai e, a partir do erguimento do Forte, o dinâmico governador mandava levantar o povoado de Albuquerque, logo acima, junto ao rio, também à margem direita, para assegurar melhor o domínio daquelas terras e servir de apoio ao Forte e aos navegantes que passavam a subir por ali, em monções vindas de São Paulo para Cuiabá [...] (CAMPESTRINI; GUIMARÃES, 1991, p. 27).

Cabe assinalar que, em diferentes momentos da história local, o rio Paraguai foi fundamental para o desenvolvimento da região. Primeiramente, nas atividades econômicas assentadas em bases coloniais, em conflitos bélicos e, posteriormente, devido às atividades comerciais realizadas com as cidades platinas viabilizadas pelas vias fluviais. Segundo Ito (2000, p. 69), após a Guerra do Paraguai ${ }^{3}$, “Corumbá totalmente destruída pela invasão paraguaia começa a sua reconstrução, sobretudo, por sediar, no período anterior ao conflito, o principal entreposto comercial de Mato Grosso".

A reconstrução de Corumbá não tardou muito, pois, em meados do século XIX, o porto da cidade era um dos que possuía o maior movimento comercial da Província. Essa situação iria ser mantida até a antiga Ferrovia Noroeste começar a se instalar no município de Corumbá, tendo chegado ao distrito de Porto Esperança em 1914 e na sede do município, na década de 1950.

A instalação da ferrovia provocou uma diminuição do movimento portuário em Corumbá, à medida que outras cidades sul-mato-grossenses tornaram-se entrepostos comerciais. A situação ainda foi agravada com a inauguração da rodovia BR 262, no trecho Corumbá a Campo Grande, e com a própria divisão do estado de Mato Grosso e consequente criação da nova Unidade Federativa (Mato Grosso do Sul), que acabou por enfraquecer o poder econômico centralizado na Cidade Branca ${ }^{4}$.

Atualmente, o município de Corumbá reúne 108.010 habitantes (IBGE, 2014) e, segundo Silva (2004, p. 19), "o saldo maior de imigrantes e descendentes estrangeiros,

\footnotetext{
${ }^{2}$ Fundada em 1778, o Arraial de 'Nossa Senhora da Conceição de Albuquerque', $1^{\circ}$ designação do vilarejo, se transformou no principal entreposto comercial da região. Foi elevada a Distrito em 1838 e a município em 1850. Por sua vez, a cidade de Ladário foi elevada a Distrito de Corumbá em 1861 e o município foi criado em $1953 . \quad$ Disponível em: <biblioteca.ibge.gov.br/visualização/dtbs/matogrossodosul/Corumbá.pdf>). Acesso em: 04 ago. 2016.

${ }^{3}$ A referência é feita à Guerra da Tríplice Aliança Guerra do Paraguai, conflito bélico que ocorreu entre os anos de 1864 e 1870 em que lutaram os países que formaram a Tríplice Aliança (Argentina, Brasil e Uruguai) contra o Paraguai.

4 'Cidade Branca' é uma das designações atribuídas à cidade de Corumbá.
} 
em Corumbá, recai, hoje, sobre os bolivianos, seguidos pelos paraguaios, uruguaios, portugueses, sírios, libaneses e palestinos".

Apesar de a população corumbaense ser bastante heterogênea, é preciso considerar que o contato com a colonização portuguesa durante diferentes momentos da história local e o pouco contato de Corumbá com o interior do Brasil favoreceram a manutenção de alguns traços linguísticos no falar da população, entre eles, o uso do /s/ sibilante. Silva $(2004)^{5}$, com base em estudo contrastivo entre dados do falar corumbaense e do português de Portugal, esclarece que "a análise feita em Portugal mostrou a evolução da pronúncia palatalizada, padrão naquele país, bem como apontou contextos de uso semelhantes aos observados nas comunidades brasileiras" (SILVA, 2004, p. 105). Além dos aspectos fonéticos, o léxico também aponta para a conservação de traços da língua transplantada pelos colonizadores portugueses. Neste estudo, discutimos a questão do uso do item lexical funda para nomear o "brinquedo feito de uma forquilha e duas tiras de borracha que os meninos usam para matar passarinhos". Essa designação foi cartografada em diferentes trabalhos geolinguísticos no Centro-Oeste brasileiro, de acordo com os dados que são apresentados na sequência.

\section{Funda: Análise dos dados geolinguísticos}

Como fonte de estudo, consultamos dois atlas linguísticos de diferentes domínios, um estadual - Atlas Linguístico de Mato Grosso do Sul (OLIVEIRA, 2007) e um local/regional - Atlas Linguístico de Corumbá e Ladário (ALENCAR, 2013). Na sequência, apresentamos, de forma sintética, as características metodológicas desses atlas.

i) Atlas Linguístico de Mato Grosso do Sul/ALMS (2007): organizado pelo professor Dr. Dercir Pedro de Oliveira, na Universidade Federal de Mato Grosso do Sul.

O ALMS teve uma rede com 32 pontos de inquérito, entrevistou 128 pessoas com o seguinte perfil: i) sexo: feminino e masculino; ii) faixa etária I (18-30 anos) e faixa etária II (45-70 anos); iii) escolaridade: rudimentar ou escolaridade até $4^{\mathrm{a}}$ série. Além disso, o informante deveria ser nascido na localidade ou nela residir desde os 8 anos de idade.

ii) Atlas Linguístico de Corumbá e Ladário/ALiCoLa (2013): produzido por Beatriz Aparecida Alencar como dissertação de mestrado, defendida na Universidade Federal de Mato Grosso do Sul, sob orientação da Profa. Dra. Aparecida Negri Isquerdo. Esse atlas contou com uma rede de cinco pontos que contemplaram "os lugares mais antigos nos municípios de Corumbá e Ladário" e situados nas principais entradas dos fluxos populacionais na região, respectivamente, localidades que se situam às margens do rio Paraguai e, preferencialmente, nas proximidades das linhas da antiga Ferrovia Noroeste.

Em relação às características do informante, foram entrevistadas 20 pessoas com o seguinte perfil: i) sexo: feminino e masculino; ii) faixa etária I (18-30 anos) e II (50-65 anos); iii) escolaridade: Ensino Fundamental. E, ainda, pessoas que fossem moradoras natas da localidade, com pouca mobilidade e com pais nascidos e residentes na mesma região linguística.

\footnotetext{
${ }^{5}$ Aspectos da pronúncia do S em Corumbá-MS: uma abordagem sociolinguística (SILVA, 2004).
} 
Na sequência, são discutidos os dados geolinguísticos registrados no ALMS e no ALiCoLa como designação do seguinte conceito: como se chama aquele brinquedo feito de uma forquilha e duas tiras de borracha que os meninos usam para matar passarinhos?

\subsection{O registro da unidade lexical funda no ALMS}

O Atlas Linguístico de Mato Grosso do Sul (ALMS) (OLIVEIRA, 2007) reuniu cinco pontos de inquérito nos municípios de Corumbá e Ladário. São eles: Paiaguás (ponto 22), Corumbá (ponto 12), Nhecolândia (ponto 20), Porto Esperança (ponto 26) e Nabileque (ponto 18).

O critério adotado no ALMS para a apresentação dos dados na legenda (registro da variação fonética e não da variação lexical) gerou um número elevado de símbolos que, por sua vez, dificultam a leitura da carta. Na verdade, a carta 0481.a reúne cinco variantes lexicais: estilingue (istilingui, estilingui, istilinga, tilingui, istilingu, istilinguis, estilingue) com 83,59\% de ocorrências; funda (fonda) com 7,81\%, além de três ocorrências únicas (chanha, baliadeira e bodoqui). Na Figura 1, a seguir, o tracejado destaca as localidades da rede de pontos onde a unidade léxica funda figura no Atlas Linguístico do Mato Grosso do Sul. A variante mais produtiva no conjunto das 32 localidades que integram a rede de pontos do ALMS é, pois, estilingue seguida de funda que se concentra nas localidades situadas no oeste do Estado.

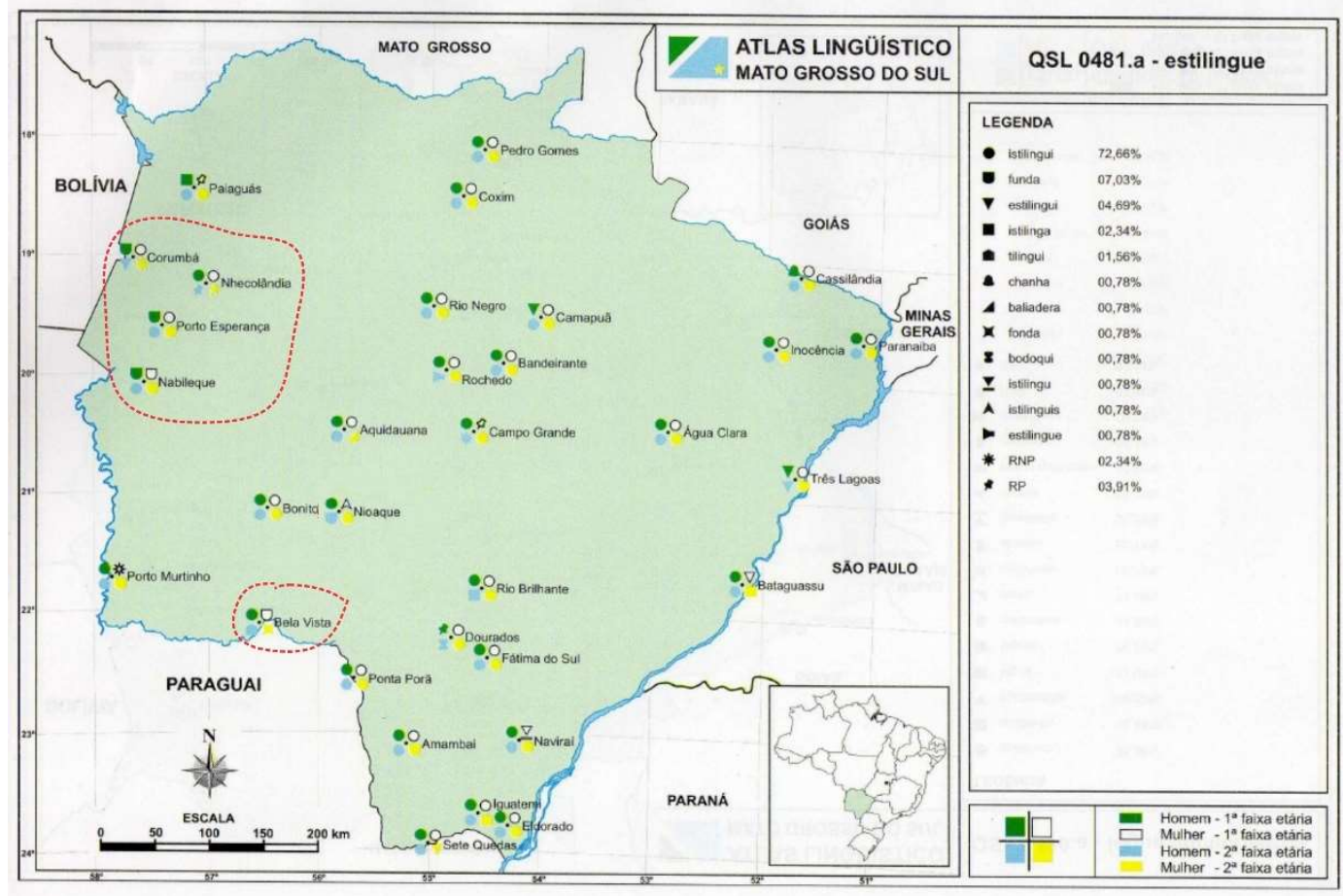

Figura 1. Carta QSL0481.a - estilingue do ALMS com destaque para as localidades com ocorrência de funda (OLIVEIRA, 2007, p. 235)

\subsection{O registro da unidade lexical funda no ALiCoLA}

O Atlas Linguístico de Corumbá e Ladário (ALENCAR, 2013) possui uma rede de pontos com cinco localidades: as sedes de município Corumbá (ponto 01) e Ladário (ponto 02) e três distritos pertencentes a Corumbá: Albuquerque (ponto 03), Porto Esperança (ponto 04) e Coimbra (ponto 05). 
No ALiCoLA (QSL 186), a unidade lexical funda foi proferida como resposta por $71,42 \%$ dos informantes, sendo citada em todas as localidades da rede de pontos, com maior ocorrência na cidade de Ladário (ponto $n^{0} 02$ ) onde foi mencionada pelos quatro informantes. Por sua vez, o item lexical estilingue figura como segunda variante mais produtiva representando $28,58 \%$ de respostas. Verifique a Figura 2:

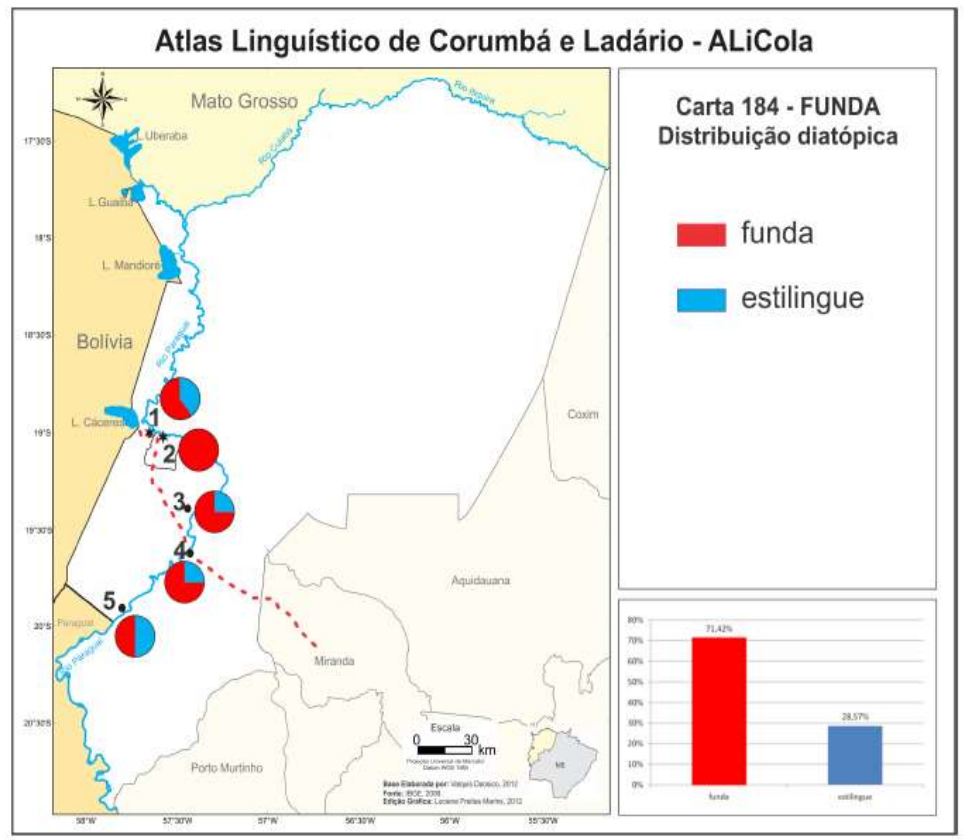

Figura 2. Carta 184 - Funda- Distribuição diatópica no ALiCoLa (ALENCAR, 2013, p. 518)

A comparação entre as cartas dos atlas tomados como fonte para este estudo demonstra que o atlas municipal confirma os dados documentados pelo atlas estadual, na região oeste de Mato Grosso do Sul. Enquanto no ALMS a unidade lexical estilingue ocupa o primeiro lugar de ocorrências $(83,59 \%)$, seguido de funda, a segunda variante mais produtiva $(7,81 \%)$, no ALiCoLa ocorre o inverso, pois funda é a primeira colocada $(71,42 \%)$ seguida de estilingue, a segunda mais produtiva (28,58\%). Apesar desse grau de frequência no panorama estadual, as ocorrências de funda são significativas para este estudo em razão das localidades em que foram documentadas, ou seja, todos os pontos em que funda foi citada estão situados no extremo oeste do estado: Bela Vista (ponto 06), Corumbá (ponto 12), Pantanal do Nabileque (ponto 18) e Porto Esperança (ponto 26).

Em tempo, é necessário pontuar a presença da unidade lexical funda nos dados do Atlas Linguístico do Brasil (ALiB), no que se refere às capitais brasileiras. A presença de funda ocorreu em apenas duas regiões: Sul (Porto Alegre e Florianópolis) e Centro-Oeste (Campo Grande e Cuiabá). Neste particular, destacam-se as respostas obtidas no CentroOeste do Brasil (Figura 3: Carta L19e), pois Corumbá e Ladário encontram-se geograficamente situadas nessa região. 


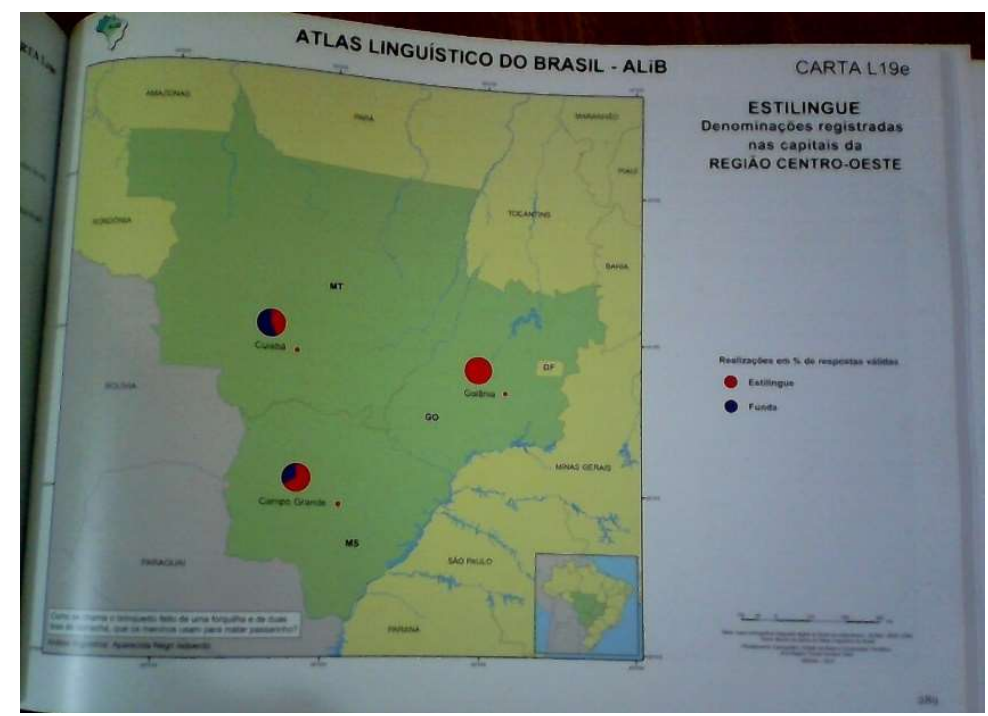

Figura 3. Carta L19e: Distribuição diatópica de funda e estilingue nas capitais da região Centro-Oeste (CARDOSO et al., 2014, p. 289)

Nota-se, na Carta L19e, a produtividade da unidade lexical funda nas capitais do Centro-Oeste brasileiro, sendo a variante predominante em Cuiabá (MT) e a segunda colocada em Campo Grande (MS). Cabe atestar também o uso da unidade lexical funda, na obra O falar cuiabano (CAMPOS, 1990).

Em relação às localidades citadas na Figura 3, relembremos a relação entre essas duas capitais com os municípios de Corumbá e Ladário, em termos históricos. Enquanto Campo Grande possui apenas 117 anos de fundação, Cuiabá acumula 297 anos de história. Ainda nesse panorama, destacam-se as seguintes informações: i) ambas as capitais estão ligadas a Corumbá em razão da divisão federativa; ii) Cuiabá, durante os momentos históricos apontados neste estudo, manteve estreitos laços com a fronteira oeste e iii) o intenso contato e intercâmbio comercial entre Corumbá e Cuiabá via fluvial (rio Paraguai e seus afluentes). Ito (2000, p. 43) destaca que o porto de Corumbá era um local muito importante para capital mato-grossense em termos de transações comerciais, pois “por ali passavam todos os produtos que abasteciam as regiões de Cáceres e Cuiabá".

Questões históricas que afetam a relação entre as capitais Cuiabá e Campo Grande, possivelmente, contribuíram para a manutenção da designação funda na norma lexical dos seus habitantes. Assim, mediante o exposto, a produtividade de funda tanto na fronteira Brasil-Paraguai quanto nas capitais do Centro-Oeste aponta para uma "marca de conservadorismo" na norma lexical dos habitantes desses espaços geográficos (ISQUERDO, 2006, p. 125).

Cabe ainda registrar que a unidade lexical funda foi produtiva entre todos os informantes entrevistados para o Atlas Linguístico de Corumbá e Ladário, independente de sexo ou idade. A Figura 4 informa o índice de ocorrência de funda entre os informantes do ALiCoLa de diferentes faixas etárias e sexo, o que demonstra a vitalidade dessa designação na norma lexical dos corumbaenses. 


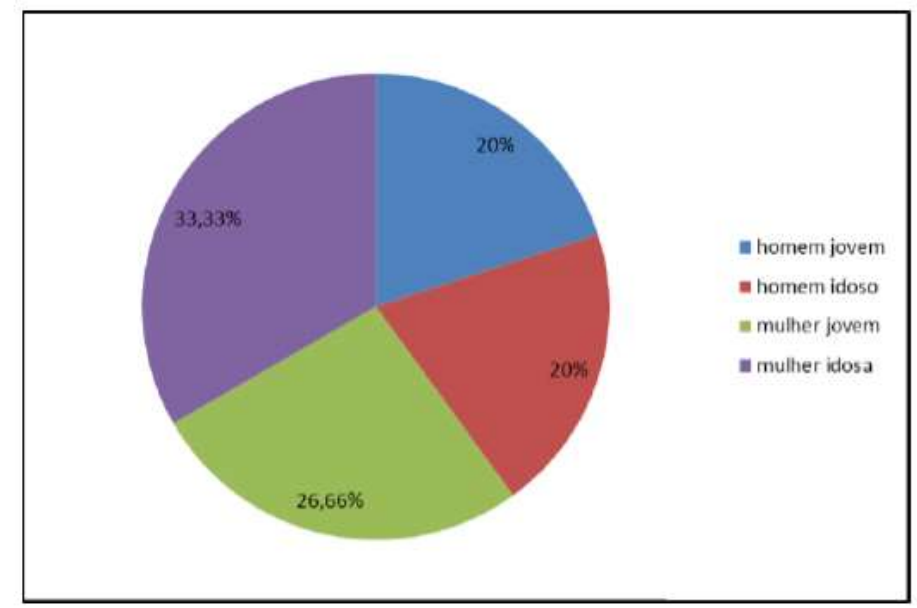

Figura 4. Representatividade de funda de acordo com o sexo e a idade dos informantes (ALENCAR, 2013, p. 100)

Além dos aspectos geolinguísticos abordados, analisamos na sequência a unidade lexical funda na perspectiva semântica.

\section{Funda: dados lexicográficos}

A unidade lexical funda figura no $\operatorname{VOLP}^{6}$ (Vocabulário Ortográfico da Língua Portuguesa) como substantivo feminino. Além disso, está registrada nos dicionários de Bluteau (1712-1728), Silva (1813), Silva Pinto (1832), Figueiredo (1899), Freire (1940), Cunha (1984), Houaiss (2001), Borba (2004), Aulete (2006) e Ferreira (2010).

No conjunto das obras lexicográficas consultadas, o item lexical funda está definido segundo diferentes acepções: i) arma de arremesso/brinquedo; ii) medicina, "dispositivo us. para conter a expansão de certas hérnias" (HOUAISS, 2001); iii) náutica "Larga cinta de gaxeta, forrada de lona, e fixada por um extremo na cabeça de um turco, servindo para abraçar a embarcação, quando suspensa nos turcos" (FIGUEIREDO, 1899) e iv) acessório: "Pl. Espécie de bôlsas em que as mulheres amparam os seios; porta-seios, estrofião: trazem tôdas nas mamas umas fundas de pano de sêda" (FREIRE, 1940).

Neste estudo, focalizamos o uso da unidade lexical funda como designação da arma de arremesso/brinquedo. No Dicionário Etimológico Nova Fronteira (CUNHA, 1982), o item léxico funda é definido como: "s.f arma de lançar pedras, catapulta XIV. Do lat. Funda//fundeiro ${ }^{1}$ s.m. 'o que fabrica fundas ou atira com elas' XV// fundIBULÁRIO XVII. Do lat. Fundibularius/fundíbulo1873. Do latfundibulus” (CUNHA, 1982, p. 371).

As obras lexicográficas de Bluteau (1712-1728), de Silva Pinto (1832) e de Silva (1813), disponíveis em<www.brasiliana.usp.br>, registram funda na acepção focalizada neste trabalho.

\footnotetext{
6 Consulta realizada no endereço eletrônico: <http://www.academia.org.br/nossa-lingua/busca-no-
} vocabulario>. Acesso em: 04 ago. 2016. 
Quadro 1. Dicionarização da unidade léxica funda em dicionários dos séculos XVIII e XIX

\begin{tabular}{|l|l|}
\hline \multicolumn{1}{|c|}{ DICIONÁRIOS } & \multicolumn{1}{c|}{ ACEPÇÕES } \\
\hline Bluteau (1712-1728) & "Instrumento de corda, que serve de atirar pedra com mayor força ...". \\
\hline Silva (1813) & $\begin{array}{l}\text { "Pedaço de coiro como uma larga fita, curto, de cujos extremos saem atilhos, } \\
\text { um envolve-se no dedo, ou mão, o outro aperta-se entre os dedos, e assim se } \\
\text { resolve, e atira a pedra que está no coiro..." }\end{array}$ \\
\hline Silva Pinto (1832) & $\begin{array}{l}\text { "s.f. Instrumento de atirar pedras. Instrumento de que se usa para sujeitar as } \\
\text { hérnias ou quebraduras". }\end{array}$ \\
\hline Figueiredo (1889) & $\begin{array}{l}\text { "s.f. Lat. funda. Aparelho feito de um pedaço de couro e de duas cordas, com } \\
\text { que se lançam pedras ou balas". }\end{array}$ \\
\hline
\end{tabular}

De acordo com o Quadro 1, é possível observar que a unidade lexical funda se configura como uma palavra bastante antiga na Língua Portuguesa, visto que está dicionarizada desde o século XVIII. Além disso, continua sendo registrada nos dicionários gerais da língua portuguesa contemporânea (séculos XX e XXI), como atesta o Quadro 2.

Quadro 2. Dicionarização da unidade léxica funda em dicionários dos séculos XX e XXI

\begin{tabular}{|l|l|}
\hline \multicolumn{1}{|c|}{ DICIONÁRIOS } & \multicolumn{1}{c|}{ ACEPÇÕES } \\
\hline Freire (1940) & "1 f. Aparelho, para arremêso de pedras ou balas". \\
\hline Houaiss (2001) & $\begin{array}{l}\text { "s.f. (SXIV cf. FichIVPM) 1. arma de arremesso constituída por uma correia, } \\
\text { ou corda dobrada, em cujo centro é colocado o objeto que se deseja lançar; } \\
\text { atiradeira, catapulta, estilingue, fundíbulo". }\end{array}$ \\
\hline Borba (2004) & $\begin{array}{l}\text { "s.f. Arma de arremesso constituída por uma correia dobrada, em cujo centro é } \\
\text { colocado o objeto que se deseja lançar, estilingue, atiradeira". }\end{array}$ \\
\hline Aulete (2006) & $\begin{array}{l}\text { "sf. 1. Arma para arremessar pedras, balas, flechas etc. feita com uma correia } \\
\text { ou corda dobrada, no centro da qual se coloca o que vai ser lançado; } \\
\text { ATIRADEIRA; CATAPULTA; ESTILINGUE". }\end{array}$ \\
\hline Ferreira (2010) & $\begin{array}{l}\text { "[Do lat. funda] S.f. 1. Laçada de couro ou de corda para arrojar pedras, ou } \\
\text { outros projetis, ao longe. [(Sin. (ant): fundíbulo]". }\end{array}$ \\
\hline
\end{tabular}

Cabe ressaltar que, ao compararmos as acepções atribuídas ao item lexical funda nas obras lexicográficas elencadas (quadros 1 e 2), destacamos a registrada pelo dicionário Houaiss (2004) ao referir-se à datação da unidade léxica analisada, no século XIV, e também destacamos a definição trazida por Ferreira (2010) que indica a origem latina do item funda.

A consulta aos dicionários demonstrou uma grande variedade de unidades lexicais consideradas sinônimas de funda, por nomearem o objeto para arremesso ou brinquedo feito de borracha com uma forquilha. O Quadro 3 reúne as variantes identificadas nos dicionários gerais e o Quadro 4, as extraídas de dicionários etimológicos e regionais. 
Quadro 3. Variantes lexicais que nomeiam a "funda" registradas em dicionários gerais da língua portuguesa

\begin{tabular}{|l|c|c|c|c|c|c|c|}
\hline $\begin{array}{l}\text { UNIDADE } \\
\text { LEXICAL }\end{array}$ & $\begin{array}{c}\text { BLUTEAU } \\
(\mathbf{1 7 1 2 -} \\
\mathbf{1 7 2 8})\end{array}$ & $\begin{array}{c}\text { SILVA } \\
\mathbf{( 1 8 1 3 )}\end{array}$ & $\begin{array}{c}\text { SILVA } \\
\text { PINTO } \\
(\mathbf{1 8 3 2})\end{array}$ & $\begin{array}{c}\text { FERREIRA } \\
\mathbf{( 1 9 8 6 )}\end{array}$ & $\begin{array}{c}\text { HOUAISS } \\
\mathbf{( 2 0 0 1 )}\end{array}$ & $\begin{array}{c}\text { BORBA } \\
\mathbf{( 2 0 0 4 )}\end{array}$ & $\begin{array}{c}\text { AULETE } \\
\mathbf{( 2 0 0 6 )}\end{array}$ \\
\hline Atiradeira & & & & $\mathrm{x}$ & $\mathrm{x}$ & $\mathrm{x}$ & $\mathrm{x}$ \\
\hline Baladeira & & & & $\mathrm{x}$ & $\mathrm{x}$ & $\mathrm{x}$ & $\mathrm{x}$ \\
\hline Bodoque & $\mathrm{x}$ & $\mathrm{X}$ & $\mathrm{X}$ & $\mathrm{x}$ & $\mathrm{x}$ & $\mathrm{x}$ & $\mathrm{x}$ \\
\hline Estilingue & & & & $\mathrm{x}$ & $\mathrm{x}$ & $\mathrm{x}$ & $\mathrm{x}$ \\
\hline Funda & $\mathrm{x}$ & $\mathrm{X}$ & $\mathrm{X}$ & $\mathrm{x}$ & $\mathrm{x}$ & $\mathrm{x}$ & $\mathrm{x}$ \\
\hline
\end{tabular}

Quadro 4. Variantes lexicais que nomeiam a "funda" registradas em dicionários etimológicos e dicionário regional

\begin{tabular}{|c|c|c|c|}
\hline \multirow{2}{*}{ UNIDADE LEXICAL } & \multicolumn{2}{|c|}{ ETIMOLÓGICOS } & REGIONAL \\
\cline { 2 - 4 } & $\begin{array}{c}\text { CUNHA } \\
(\mathbf{1 9 8 2})\end{array}$ & $\begin{array}{c}\text { GUÉRIOS } \\
(\mathbf{1 9 7 9 )}\end{array}$ & $\begin{array}{c}\text { ORTÊNCIO } \\
(\mathbf{1 9 8 3 )}\end{array}$ \\
\hline Atiradeira & & & $\mathrm{X}$ \\
\hline Baladeira & & & $\mathrm{X}$ \\
\hline Bodoque & $\mathrm{X}$ & & $\mathrm{X}$ \\
\hline Estilingue & $\mathrm{X}$ & $\mathrm{X}$ & \\
\hline Funda & $\mathrm{X}$ & & \\
\hline
\end{tabular}

Nota-se que, apesar de a unidade lexical funda ser registrada em dicionários de diferentes tipologias produzidos em épocas distintas, não foi registrada no Dicionário de Etimologia da Língua Portuguesa (GUÉRIOS, 1979) e no Dicionário do Brasil Central (ORTÊNCIO, 1983). O Dicionário do Folclore (CASCUDO, 2005), por seu turno, registra as seguintes entradas lexicais como denominação do brinquedo em pauta: atiradeira, baladeira, bodoque, funda e estilingue.

\section{Considerações finais}

Neste estudo, foi possível constatar que algumas localidades do Mato Grosso do Sul têm grande importância no panorama histórico, situação que se reflete diretamente no léxico local. Dentre as realizações da linguagem que ocorrem nas cidades de Corumbá e Ladário, destacamos, aqui, a presença da unidade lexical funda, datada do século XIV e com origem latina. Este item pode ser considerado uma herança lusa que se manteve em algumas localidades do Centro-Oeste brasileiro.

A permanência da unidade léxica funda foi confirmada pelos trabalhos geolinguísticos realizados no Centro-Oeste brasileiro, sobretudo nas cidades de Corumbá e Ladário. No ALiCoLa, aparece com alta produtividade; no ALMS, na região de fronteira Brasil/Paraguai, no município de Corumbá. Considerando os dados nacionais, o Atlas Linguístico do Brasil documenta a presença de funda nas capitais Campo Grande (MS) e Cuiabá (MT) que, por razões históricas, evidenciam nos diferentes níveis da língua traços conservadores do português europeu.

Além disso, destaca-se a vitalidade do item lexical funda nas diferentes faixas etárias da população de Corumbá e de Ladário, o que aponta para uma possível manutenção da unidade léxica funda na norma lexical dos corumbaenses. 


\section{REFERÊNCIAS}

ACADEMIA BRASILEIRA DE LETRAS. VOLP - Vocabulário Ortográfico da Língua Portuguesa. Disponível em: <http://www.academia.org.br/nossa-lingua/busca-novocabulario $>$. Acesso em: 28 ago. 2015.

ALENCAR, B. A. Atlas Linguístico de Corumbá e Ladário: uma descrição da língua portuguesa falada no extremo oeste de Mato Grosso do Sul. 2013. 620 f. Dissertação (Mestrado em Estudos de Linguagens) - Universidade Federal de Mato Grosso do Sul, Campo Grande, 2013.

AULETE, C. Dicionário Contemporâneo da Língua Portuguesa. Versão eletrônica. Rio de Janeiro: Editora Lexikon, 2006.

BORBA, F. Dicionário UNESP do Português Contemporâneo. São Paulo: Editora UNESP, 2004.

BLUTEAU, R. Vocabulario portuguez \& latino: áulico, anatômico, architectonico... Coimbra: Collegio das Artes da Companhia de Jesus, 1712-1728.

CASCUDO, L. da C. Dicionário do Folclore Brasileiro. São Paulo, Editora Global, 2012.

CAMPOS, C. O Falar Cuiabano. Cuiabá: Editora Carlini e Caniato, 1990.

CAMPESTRINI, H.; GUIMARÃES, A. V. História de Mato Grosso do Sul. 2. ed. Campo Grande: Editora UFMS, 1991.

CARDOSO, S. Geolinguística: Tradição e modernidade. São Paulo: Parábola, 2010.

CUNHA, A. G. da. Dicionário Etimológico Nova Fronteira da Língua Portuguesa. 2. ed. Rio de Janeiro: Nova Fronteira, 1986.

FERREIRA, A. B. de H. Novo Dicionário Aurélio da Língua Portuguesa. Curitiba: Positivo, 2010.

FIGUEIREDO, C. de. Novo dicionário da Língua Portuguesa. Lisboa: Imprensa Portugal-Brasil, 1899.

FREIRE, L. Grande e novíssimo dicionário da Língua Portuguesa, v. IV. Rio de Janeiro: A noite Editora, 1940.

GUÉRIOS, R. F. M. Dicionário de etimologias da Língua Portuguesa. Curitiba: Ed. Nacional, 1979.

HOUAISS, A. Dicionário Eletrônico Houaiss da Língua Portuguesa. Rio de Janeiro: Editora Objetiva, Instituto Antonio Houaiss, 2001.

INSTITUTO BRASILEIRO DE GEOGRAFIA E ESTATÍSTICA. Disponível em: $<$ http://cidades.ibge.gov.br/painel/painel.php?lang=\& codmun $=500320 \&$ search $=\mid$ corumb a>. Acesso em: 28 ago. 2015.

INSTITUTO BRASILEIRO DE GEOGRAFIA E ESTATÍSTICA. Disponível em: $<$ biblioteca.ibge.gov.br/visualização/dtbs/matogrossodosul/Corumbá.pdf>. Acesso em: 08 abr. 2017.

ISQUERDO, A. N. Lexicografia e Geolinguística: Interfaces. In: MARTINS, E. S.; CANO, W. M.; FILHO, W. B. M. (Org.). Léxico e Morfofonologia: perspectivas e análises. Uberlândia: EDUFU, 2006. p. 113-134. 
ITO, C. A. Corumbá: o espaço da cidade através do tempo. Campo Grande: Editora da UFMS, 2000.

MARTINS, G. R. Breve painel etno-histórico de Mato Grosso do Sul. Campo Grande: Editora da UFMS, 2002.

OLIVEIRA, D. P. (Org.). Atlas Linguístico do Mato Grosso do Sul (ALMS). Campo Grande: Editora da UFMS, 2007.

ORTÊNCIO, B. Dicionário do Brasil Central. São Paulo: Editora Ática, 1983.

SILVA, A. de M. Diccionario da língua portugueza. Rio de Janeiro: Francisco Alves, 1922. Fac-símile da segunda edição. Lisboa: TypographiaLacérdina, 1813. 2 volumes.

SILVA, R. V. da. Aspectos da pronúncia do "S" em Corumbá- MS: uma abordagem sociolingüistica. Campo Grande: Editora da UFMS, 2004.

SILVA PINTO, L. M. da. Diccionario da Lingua Brasileira. Typographia de Silva, 1832.

Recebido em: 02/09/2016

Aprovado em: 12/04/2017 